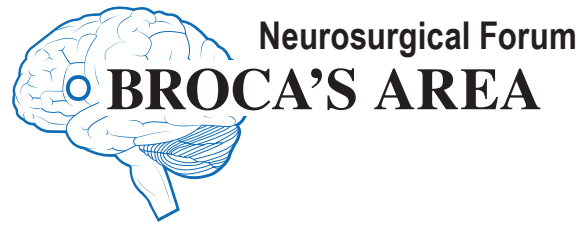

\section{A raised bar for aneurysm surgery in the endovascular era}

\author{
M. Yashar S. Kalani, MD, PhD, John E. Wanebo, MD, \\ Nikolay L. Martirosyan, MD, PhD, Peter Nakaji, MD, \\ Joseph M. Zabramski, MD, and Robert F. Spetzler, MD
}

Department of Neurosurgery, Barrow Neurological Institute, St. Joseph's Hospital and Medical Center, Phoenix, Arizona

$\mathrm{W}$ HILE microsurgical treatment of cerebral aneurysms has a rich and documented history of success, the impressive progression of endovascular technology, techniques, and skill has permanently altered the paradigm for treating intracranial aneurysms. The results of the International Subarachnoid Aneurysm Trial (ISAT) $)^{23}$ and the Barrow Ruptured Aneurysm Trial $(\text { BRAT) })^{22}$ and its follow-up studies, ${ }^{35,36}$ even with the noted flaws in selection bias and crossover, have threatened to make open surgical treatment of cerebral aneurysms a relic. However, despite the successes of endovascular therapy, not all aneurysms are amenable to endovascular treatment, if for no other reason than simply because of safety concerns. Now the pendulum has swung back toward the middle with the publication of long-term evaluations of the durability of endovascular treatment showing evidence of delayed hemorrhages or growth of coiled aneurysms in endovascularly treated patients., Nonetheless, endovascular techniques provide a less invasive alternative to cerebrovascular surgery for aneurysms, and neurosurgeons now have a new standard of care to meet-that provided by endovascular management of cerebral aneurysms.

The rapid introduction of endovascular tools and techniques has revolutionized treatment for patients with a diverse array of vascular pathologies. From the Stentriever (Stryker Corp.) and thrombectomy tools for stroke $5,6,13,15,33$ to the introduction of liquid embolic agents (Onyx; Covidien, LP) for embolization of vascular malformations and cancers ${ }^{8,31}$ and flow-diverting stents for complex cerebral aneurysms, ${ }^{24}$ endovascular tools have impressively revolutionized the treatment of these pathologies over the past decade. These neurointerventional techniques have indeed raised the bar for open aneurysm surgery and have prompted cerebrovascular surgeons to innovate and push for refinement, minimization of morbidity, and continued durability of treatment associated with aneurysm surgery. Thus, during the same period, surgical advances have continued to make microsurgery-the most durable technique for treating aneurysms-safer, more cosmetically appealing, and less invasive. 9

Despite rapid advances in endovascular techniques, there remain patients with aneurysms who are not ideal candidates for endovascular treatment, although they are still treated with these techniques, often because of a lack of availability of a surgeon who is well versed in and comfortable with open surgery. In an era when most of the trainees in North American neurosurgery residency programs complete their training for surgical treatment of aneurysms after having treated fewer than 50 aneurysms, maintaining excellence while continuing to teach microsurgical treatment of aneurysms remains both a necessity and a priority. Herein, we review advances in surgical treatment of aneurysms and highlight the importance of continued training in microsurgical techniques.

\section{Minimally Invasive Tailored Craniotomies}

The field of skull base and cerebrovascular surgery has witnessed a transition from large craniotomies that provided extensive views of the anatomy at the skull base to more tailored approaches that minimize brain exposure while continuing to provide adequate visualization without marginalizing safety. ${ }^{11,14,26,29}$ The trend toward miniaturization of craniotomies stems from patient demand for better cosmesis. ${ }^{30}$ Improvements in microscopes and surgical instrumentation and the incorporation of neuronavigation into surgical treatment paradigms for aneurysms have allowed surgeons to expose vascular lesions safely while minimizing morbidity to the adjacent brain. ${ }^{37}$ Although to date, no randomized trial has documented decreased use of pain medications or improved cosmetic outcomes with smaller openings, and there are unlikely to be any such trials, experience has demonstrated shorter 
lengths of stay and improved subjective patient satisfaction with the use of tailored craniotomies compared with the use of larger skull base approaches. ${ }^{30}$

Tailored craniotomies are particularly appropriate for cerebral aneurysm surgery, given that most of these lesions reside at a depth from the skull opening, which renders them particularly attractive for such an approach (Fig. 1).
Tailored, minimally invasive craniotomies do not violate the basic tenets of aneurysm surgery. With a tailored approach, the surgeon can readily obtain proximal and distal control, perform dissection of perforators and the aneurysm neck, and close and obliterate the aneurysm without risk to the patient. When a tailored or "keyhole" craniotomy is used, patient positioning is of paramount impor-

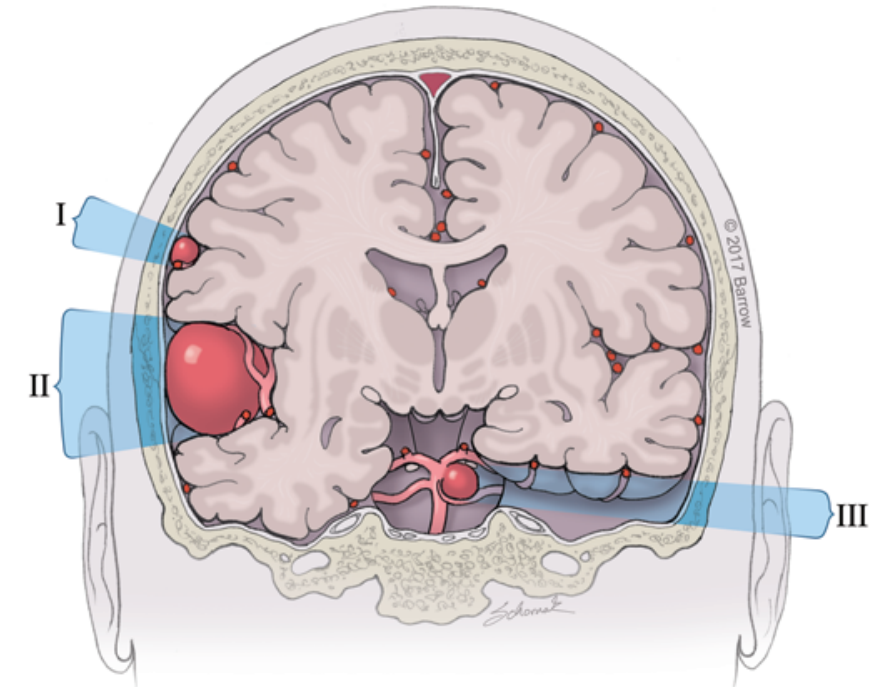

A

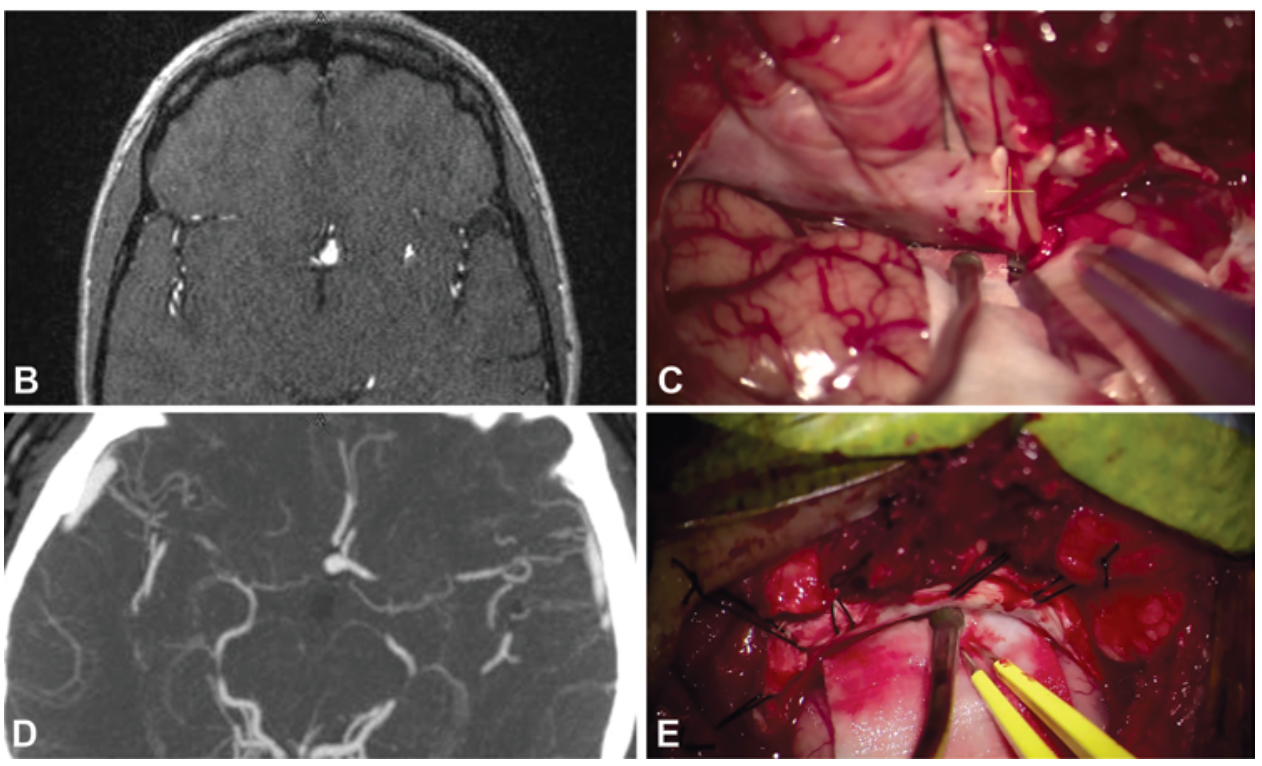

FIG. 1. The "keyhole" concept and tailored minimally invasive skull base approaches. The keyhole concept is based on the premise that minimizing trauma to structures in the operative path of the surgeon facilitates performance of a safe and effective operation. However, the association of the keyhole concept with small craniotomies is a misconception. A keyhole approach provides the smallest, most meticulous opening necessary to perform an operation. A: Artist's illustration showing examples of keyhole approaches. A keyhole craniotomy for a cortical lesion should be the size of the lesion (I and II) and, by necessity, may be large (II). For deep-seated lesions (III), the superficial opening can be minimized because more cortical exposure gains the surgeon little at the operative depth. Minimally invasive skull base approaches create a less traumatic exposure without sacrificing the working angles and surgical degrees of freedom necessary to safely approach and treat lesions. B and C: Preoperative MR angiogram (B) and intraoperative photograph (C) of an unruptured anterior communicating artery aneurysm treated using an orbitozygomatic approach. D and E: Preoperative CT angiogram (D) and intraoperative photograph (E) of a similar aneurysm treated using a keyhole supraorbital craniotomy. Instruments in photographs provide perspective. For simple, unruptured aneurysms, the addition of the larger skull base craniotomy adds little for exposure and treatment of the aneurysm. With ruptured aneurysms, brain edema may necessitate a larger opening. Panels A, C, and E are used with permission from Barrow Neurological Institute. Figure is available in color online only. 
tance; an operation may not be performed adequately if the patient's head and body are not optimally positioned. In many instances, when a larger craniotomy is required, the surgeon may obtain required surgical corridors even if the patient is not optimally positioned, given the availability of many more working angles. However, when the neurosurgeon devotes the necessary time to optimize patient positioning, the use of keyhole approaches can provide excellent exposure and control over the vasculature. Since the introduction of endoscopy, its use in the treatment of cerebral aneurysms has slowly been gaining acceptance, and it continues to be cautiously explored in select centers. ${ }^{12}$ The improved illumination provided by the use of the endoscope, particularly at the depth of a surgical field, can greatly assist dissection; however, great care should be taken in patient selection. Other adjuncts that help with illumination at the depth of the surgical field include lighted instruments, such as bipolar forceps and suction devices (Fig. 2).

\section{Retractorless Surgery}

Brain retractors have been a cornerstone of operative setups for aneurysm surgery. The use of retractors allows the surgeon to mobilize the lobes of the brain and gently retract them, exposing the surgical corridors necessary to tackle lesions, especially at depth. Undoubtedly, there are cases in which the use of fixed retractors is critical to the proper execution of an operation. However, retractors are not harmless tools. The placement of retractors can result in microcirculation spasms, resulting in ischemia and signal change on MRI studies. ${ }^{20}$

An alternative to fixed retractors is the use of dynamic retraction (Fig. 3). Dynamic retraction is the process of using the shaft of the suction and bipolar devices or microinstruments to mobilize the brain. ${ }^{37}$ Although these devices allow for retraction, they do so dynamically without placing extensive undue traction on the brain or adjacent vasculature. The abandonment of fixed retractors avoids chronic pressure ischemia in the surrounding brain. It also prevents the inadvertent and potentially disastrous effects of a bumped retractor. The dangers of manipulating arteries that are being stretched by a fixed retractor, such as an arterial tear or aneurysm dome disruption, are well recognized by most surgeons, although such consequences are likely underreported in the medical literature.

The "retractorless" surgery technique has a learning curve and takes practice, but it can be readily learned, as demonstrated by the fellows and residents at our institution. The surgeon must adapt to using the nondominant hand to wield a retractor and a suction device. Techniques that free the hands, such as the use of a mouthpiece to adjust the microscope focus and region of attention, play a larger role. Foot controls for microscope focus and zoom and to adjust chair position also may assist in dissection without a retractor. However, a complete understanding of the $3 \mathrm{D}$ anatomy of the case at hand is perhaps what is most important. Knowing where a perforator or main arterial branch is relative to the neck and dome of the aneurysm is essential when the entire operative field cannot be seen all at once. Through dynamic movement of the suction device and adjustment of the angles of the microscope, a
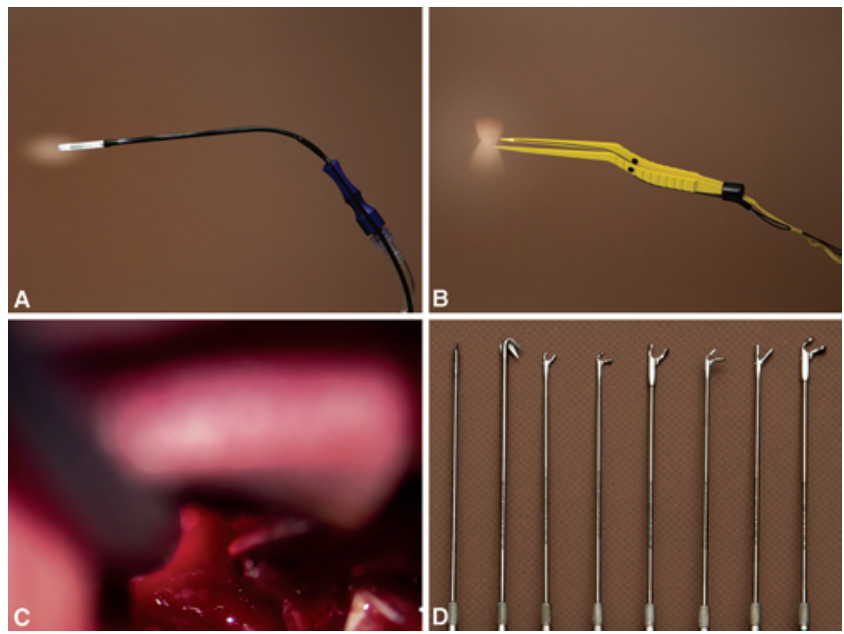

FIG. 2. Novel surgical instruments. A-C: The use of a lighted suction device $(A)$ and lighted bipolar forceps $(B)$ provides the surgeon with improved illumination at the depth of narrow, deep surgical corridors (C). D: Single-shaft, bayonetted instruments further assist in operation at depth without hindering visualization. Used with permission from Barrow Neurological Institute. Figure is available in color online only.

surgeon can maximize his or her understanding of the patient's anatomy prior to performing definitive moves, such as final clipping, and can prepare to work safely within a limited field.

Skull base techniques (e.g., removal of the superior and lateral orbit, the clinoid, the zygoma, or the medial occipital condyle) create a working space that reduces the need for a fixed retractor. Adjusting the microscope's line of sight directly toward the aneurysm neck while the clip applier enters the arena from another trajectory maximizes the critical view that is needed and allows unobstructed light into a deep field. The use of a dental mirror or a $45^{\circ}$ endoscope allows for inspection of anatomy before and after clipping in small deep spaces.

At times, however, a rigid retractor is the key to a safe and effective aneurysm clipping. Surgeons must always be ready to use a retractor when circumstances dictate. Early in the surgeon's retractorless surgical experience, the need for a retractor at the final stage of clipping is more common. A balance must be achieved between progress and what works best in the surgeon's hands. At our center, we have abandoned the routine use of fixed retraction for aneurysm surgery except in rare cases.

\section{Adjuncts for Aneurysm Exposure}

In addition to improvements in surgical opening, several newly introduced adjuncts have reduced the extent of traumatic subarachnoid exposure previously required to treat cerebral aneurysms. Among these innovations is hydrodissection to assist with opening the sylvian and interhemispheric fissures. When combined with sharp microdissection, such techniques allow potential spaces in the brain to be readily developed without injury to, or undue manipulation of, the brain.

The judicious use of hemostatics, such as FLOSEAL (Baxter Healthcare Corp.), and fibrin sealants, such as EVICEL (Ethicon, Inc.), allows surgeons to control bleed- 

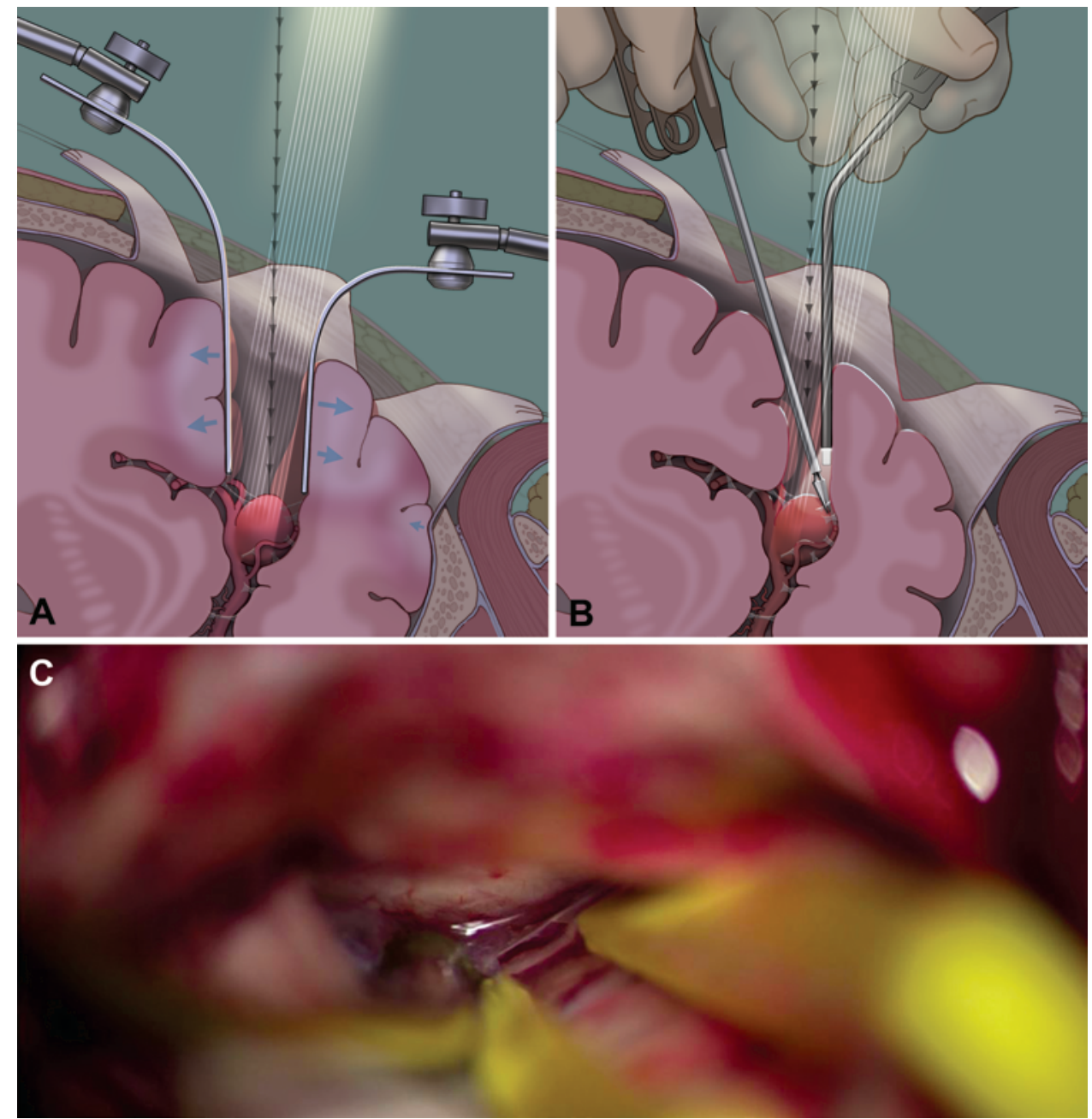

FIG. 3. Dynamic retraction and retractorless surgery. A and B: Artist's illustrations demonstrating fixed (A) and dynamic (B) retraction. Fixed retractors are a cornerstone of aneurysm treatment and allow the surgeon an unhindered view of the inflow, outflow, and parent vessels during dissection and clipping of aneurysms. Given their fixed nature, these retractors may result in pressure-induced ischemic changes in the area where retraction is applied. Dynamic retraction afforded by the shafts of surgical instruments similarly allows the surgeon to visualize the surgical field, but the act of dynamic retraction minimizes injury to the underlying brain. C: Intraoperative photograph demonstrating the dynamic retraction of the frontal lobe using bipolar cautery and suction devices. Used with permission from Barrow Neurological Institute. Figure is available in color online only.

ing and minimize the use of cautery. Such adjuncts can be especially helpful in rare encounters with the cavernous sinus or the prevertebral venous plexus.

\section{Circulatory Arrest}

Circulatory arrest is an important adjunct for treatment of difficult cerebral aneurysms. ${ }^{27}$ When used in properly selected patients, circulatory arrest greatly facilitates surgical treatment of aneurysms, but it harbors a high risk of complications. Thus, its use has largely been abandoned, especially since the development of endovascular alternatives. The introduction of adenosine has transformed circulatory arrest from an invasive procedure to one that is much better tolerated, safer, and more transient, but still reproducible in most operating rooms. ${ }^{4}$ Administration of adenosine allows the surgeon to decrease flow into the aneurysm, which is necessary to obtain proximal and distal control, or it provides the relaxation required to allow proper placement of the clip across the neck of the aneurysm (Fig. 4).

\section{Intraoperative Confirmation of Aneurysm Occlusion}

The introduction of several new tools has improved verification of aneurysm occlusion and patency of other vasculature during aneurysm surgery while decreasing reliance on intraoperative angiography. The routine use of indocyanine green (ICG) angiography ${ }^{28}$ allows the surgeon to document aneurysm occlusion; the patency of inflow, outflow, and perforating vessels; and the need for clip repositioning (Fig. 5). Although intraoperative angiography ${ }^{40,41}$ remains the gold standard for documenting aneurysm occlusion, its invasive nature, difficulty in cases where the patient is prone, and challenging access have resulted in reduced use of this technique at our center. Another adjunct that can be used to assess the safety and efficacy of intraoperative clipping is the handheld Doppler 

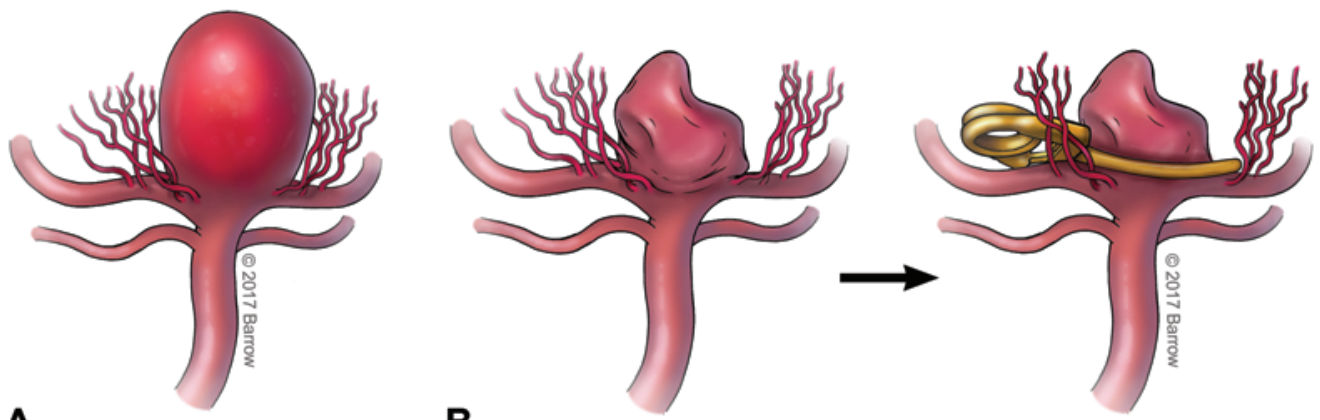

A

B
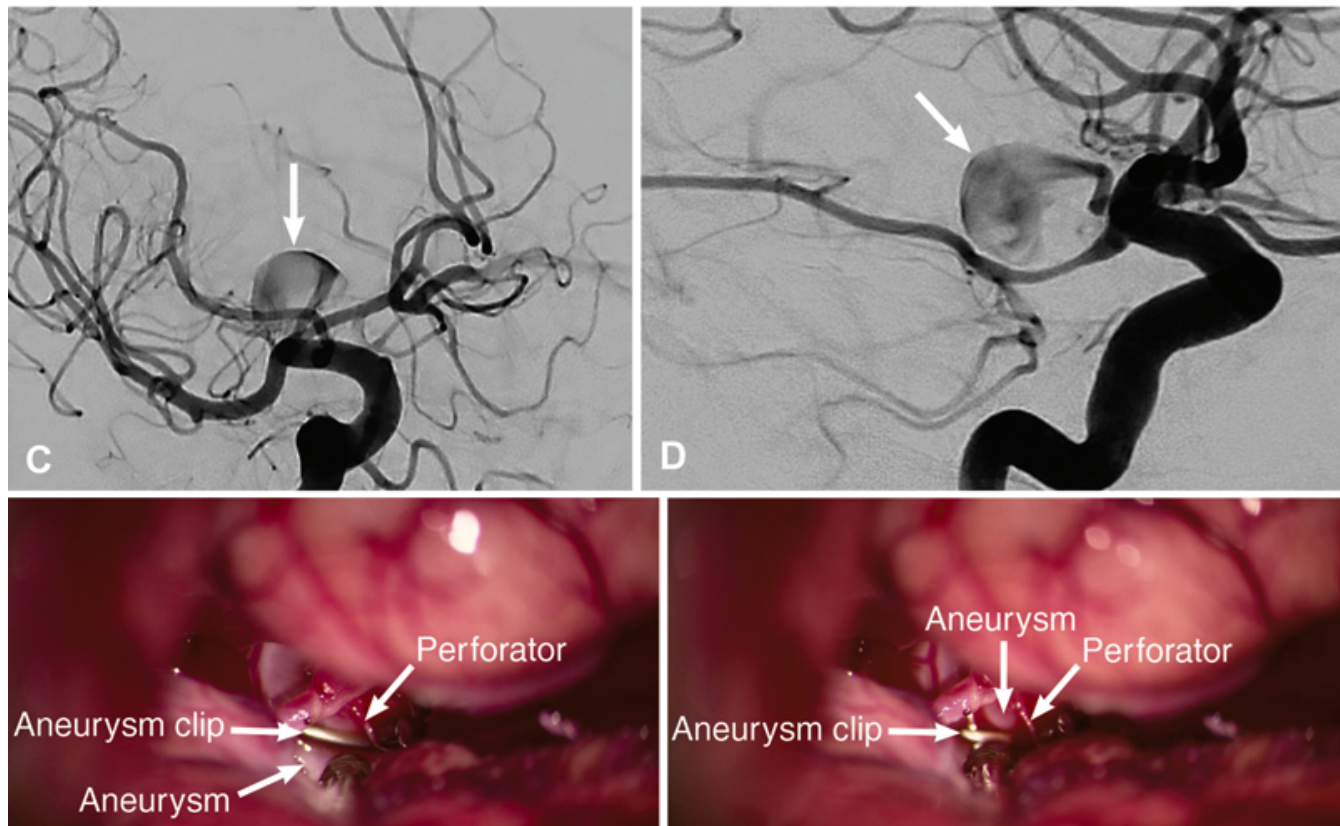

E
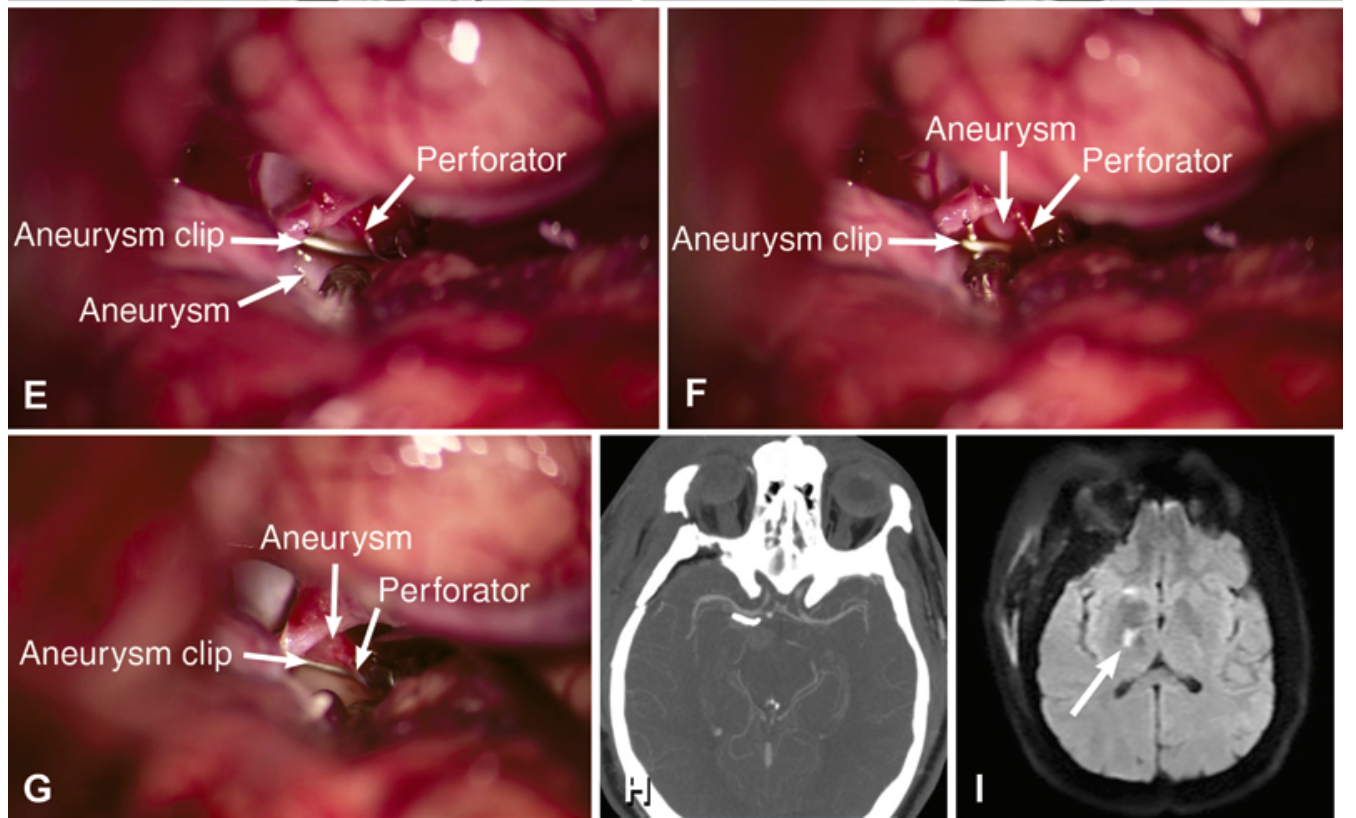

FIG. 4. Pharmacological temporary circulatory arrest. A and B: Artist's illustrations demonstrating the use of pharmacological circulatory arrest to facilitate clip application. In cases where temporary clip application may not otherwise be possible (A), the use of pharmacological temporary circulatory arrest may collapse the turgid dome of the aneurysm (B). Temporary circulatory arrest afforded by the administration of chemicals (e.g., $0.3-0.4 \mathrm{mg} / \mathrm{kg}$ adenosine) provides the surgeon with enough time to apply the final clip construct in select cases. C-I: Images from the case of a 38-year-old man with a history of a basal ganglia infarct on the right side who presented to our vascular service for consultation. His deficits had completely resolved and he was neurologically intact. Anteroposterior (C) and lateral (D) right carotid artery angiograms demonstrate an anterior choroidal artery aneurysm (arrows) measuring $1.4 \times 1.1 \mathrm{~cm}$. Given the dysplastic nature of the parent vessel, this aneurysm was not amenable to endovascular treatment and the patient was taken to the operating room for surgical sacrifice of the parent vessel. Intraoperatively $(E)$, the large size of the aneurysm made it difficult to apply the clip necessary to occlude the vessel without risking injury to perforators that arose proximally from the vessel. Administration of adenosine caused the aneurysm dome to collapse $(F)$, so that the clip could be applied at a location that avoided sacrifice of critical perforators $(G)$. Postoperative axial $C T$ angiography $(H)$ demonstrates complete occlusion of the aneurysm and the dysplastic distal vessel. Diffusion-weighted MR image (I) shows a small infarct (arrow), but the patient was neurologically intact at his baseline, with no sequela from the vessel sacrifice. Panels $A, B$, and $E-G$ are used with permission from Barrow Neurological Institute. Figure is available in color online only. 

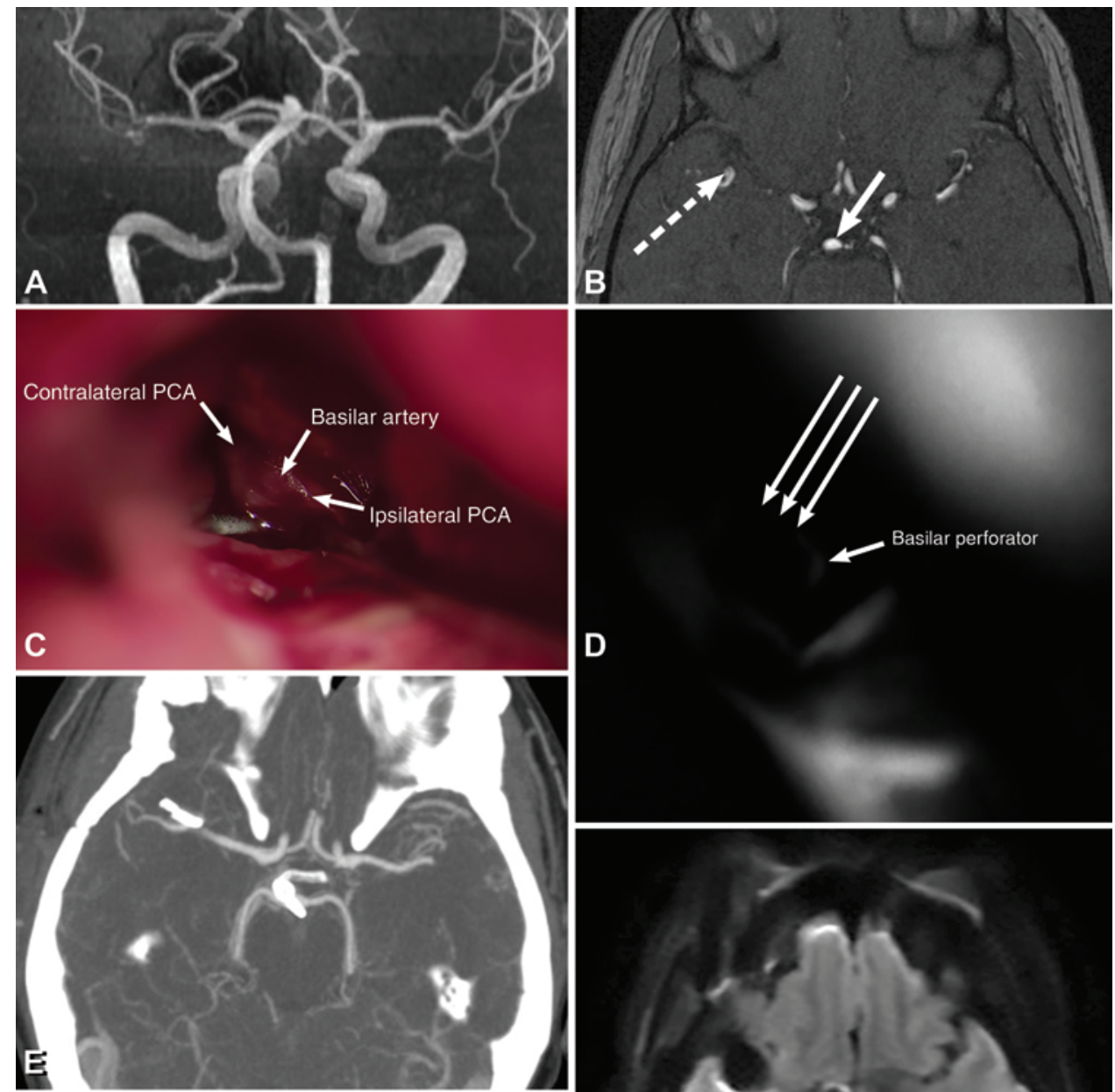

D
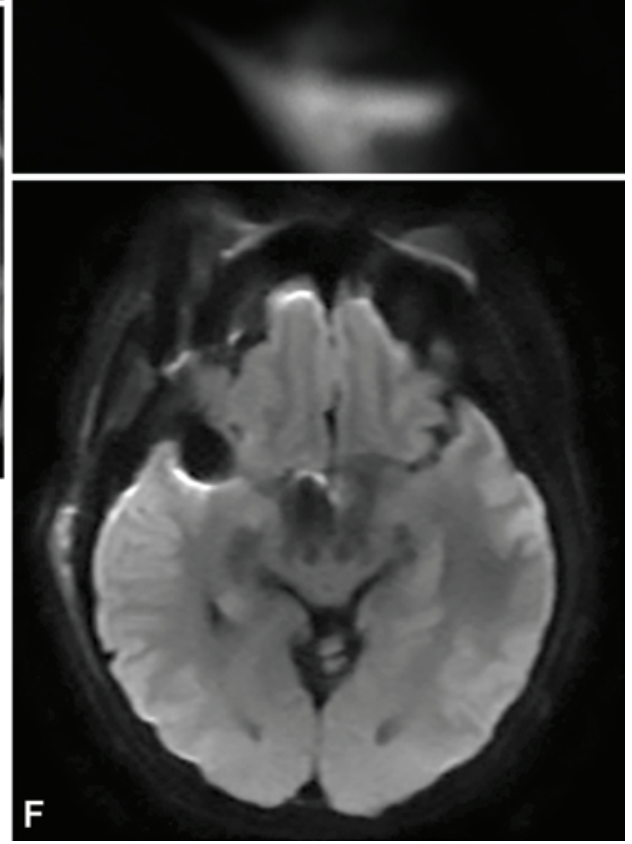

FIG. 5. Intraoperative confirmation of aneurysm occlusion. ICG angiography has revolutionized the intraoperative confirmation of aneurysm occlusion and patency of en passage vessels. The administration of the dye by the anesthesiologist allows the surgeon to confirm aneurysm occlusion and preservation of inflow, outflow, perforator, and adjacent vasculature. In select cases, the results of the ICG study may indicate that the surgeon should modify the clip placement. The ICG dose used at our institution is limited to $0.2-0.5 \mathrm{mg} / \mathrm{kg}$. A and B: MR angiography (MRA) reconstruction views obtained in a 61-year-old woman who presented to our service for neurosurgical consultation. The patient's medical history was significant for hypertension and her social history was significant for more than 40 pack-years of smoking. The MRA study revealed a wide-neck 6-mm aneurysm of the basilar apex ( $\mathrm{B}$, solid arrow) and a smaller 4-mm aneurysm of the right middle cerebral artery bifurcation (B, dashed arrow), and the patient was taken to the operating room for surgical clipping of both aneurysms using a right modified orbitozygomatic craniotomy. C: Intraoperative photograph demonstrating clip occlusion of the basilar apex aneurysm. D: ICG angiogram demonstrating complete occlusion of the aneurysm (long arrows) with preservation of flow in the perforator (short arrow) arising from the basilar apex. E: Postoperative axial CT image demonstrating complete occlusion of the aneurysms. F: Axial diffusion-weighted MR image demonstrating no stroke in the territory of the basilar perforators. $P C A=$ posterior cerebral artery. Panels $C$ and $D$ are used with permission from Barrow Neurological Institute. Figure is available in color online only. 

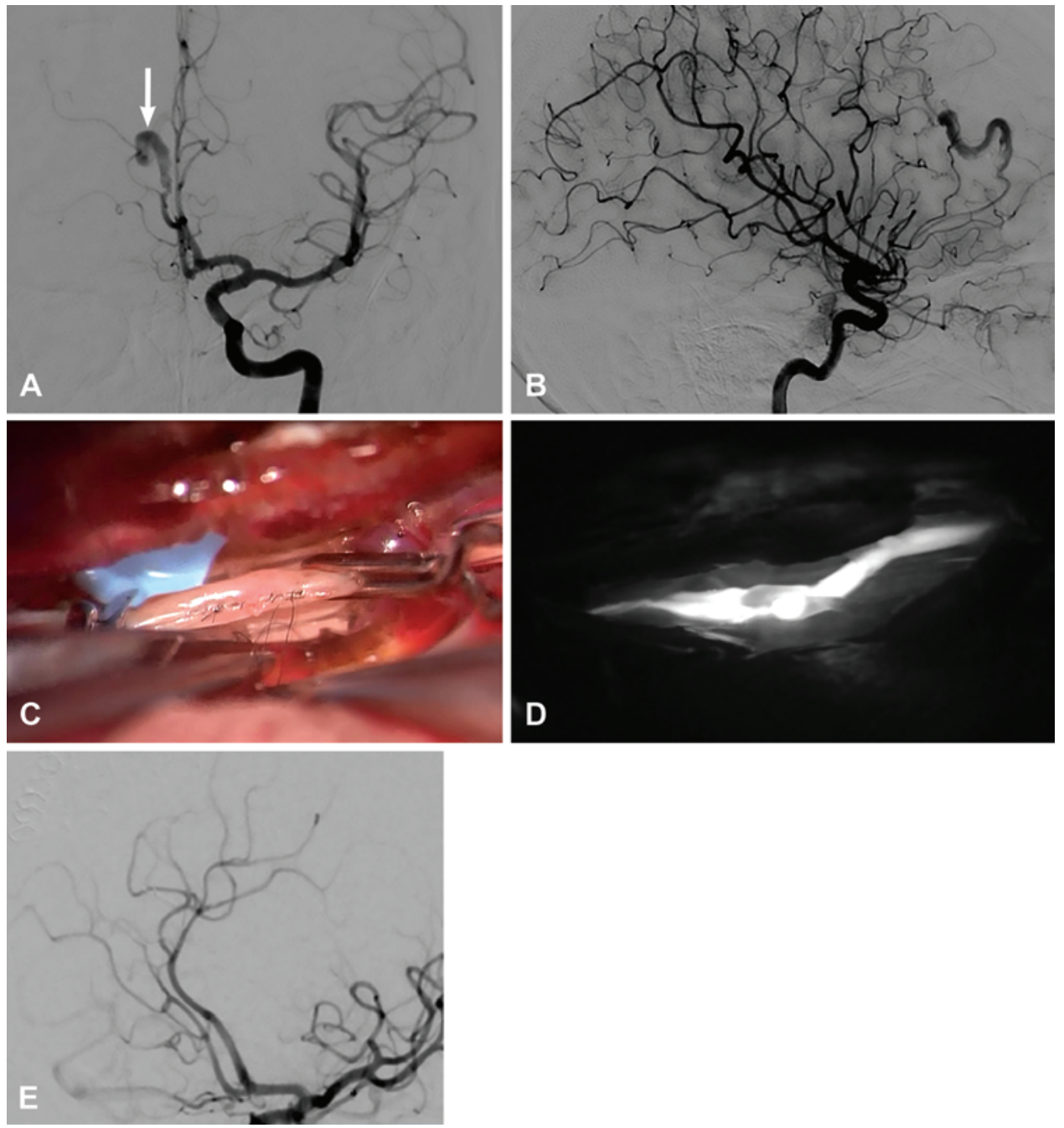

FIG. 6. Cerebral revascularization for complex aneurysms. Despite a decrease in indications for cerebral revascularization, bypass surgery remains an essential tool in the treatment of select, complex aneurysms that may not be amenable to direct clipping or endovascular treatment. A previously healthy 31-year-old woman with a history of subarachnoid hemorrhage 3 months earlier presented to our service for treatment of a complex, fusiform aneurysm of the anterior cerebral artery. The patient did not have this aneurysm treated at the time of hemorrhage and had regained all neurological function by the time of presentation to our center. A and B: Anteroposterior (A) and lateral $(B)$ carotid artery angiograms demonstrating a fusiform aneurysm of the postcommunicating segment of the right anterior cerebral artery (A, arrow). C and D: Intraoperative images. The patient underwent an interhemispheric craniotomy for exposure of the aneurysm. Ultimately, the inflow to the diseased segment of the vessel was sacrificed and the patient underwent an $\mathrm{A}_{3}-\mathrm{A}_{3}$ side-to-side bypass for revascularization of the distal anterior cerebral artery territory. The intraoperative photograph $(\mathrm{C})$ demonstrates the side-to-side anastomosis of the distal anterior cerebral arteries. The ICG angiogram (D) demonstrates patency of the bypass and flow in the distal territory. E: Postoperative carotid angiography demonstrating occlusion of the diseased segment of the vessel and flow in the distal anterior cerebral artery circulation via the patent bypass. The patient was neurologically intact postoperatively. Panels $C$ and $D$ are used with permission from Barrow Neurological Institute. Figure is available in color online only.

ultrasonography probe, which documents cerebral blood flow. ${ }^{34}$

\section{Revascularization Techniques for Difficult Aneurysms}

Despite improvements in endovascular tools, revascularization remains an essential tool for the most complicated aneurysms. Cerebral revascularization has undergone a renaissance with the introduction of alternatives to the superficial temporal artery-to-middle cerebral artery bypass. ${ }^{16-18}$ Newer bypass techniques, such as intracranial- to-intracranial bypass surgery, ${ }^{32}$ obviate the need for an extracranial donor vessel, often provide a shorter bypass length, and in most cases do not require a graft, which minimizes the likelihood of occlusion (Fig. 6). The introduction of shorter segment grafts for high-flow bypasses, such as the maxillary artery-to-middle cerebral artery bypass, ${ }^{1,25}$ allows the surgeon to replace significant flow to the cerebrum without the need for neck dissection or extensive drilling of the skull base. Furthermore, the addition of nonocclusive bypass techniques, such as excimer laser-assisted nonocclusive anastomosis, ${ }^{38,39}$ provides new 

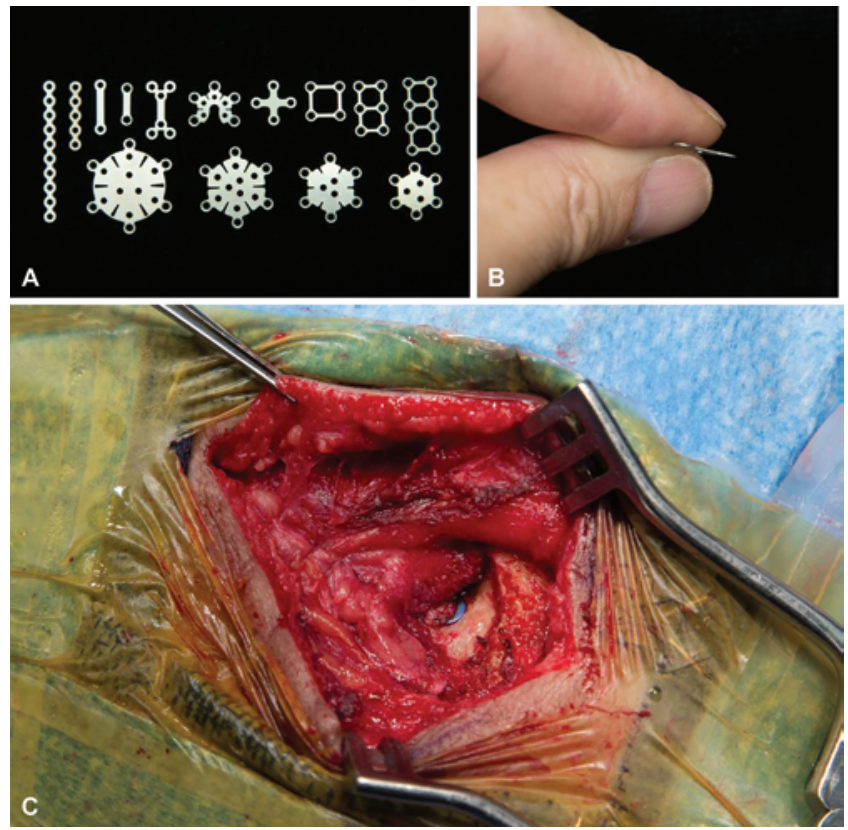

FIG. 7. Novel adjuncts for reconstruction and improved cosmesis. Low-profile plating systems (A and B) allow for improved cosmesis and minimal visibility, as well as reduced palpability by the patient (C). Panel $C$ is used with permission from Barrow Neurological Institute. Figure is available in color online only.

possibilities for revascularization in patients at risk for ischemic injury during temporary occlusion.

\section{Reconstruction and Closure}

The dictum that patients judge the outcome of an operation by their cosmetic outcome holds true for aneurysm surgery. To improve cosmetic outcomes, surgeons have attempted to limit their use of bone opening and soft tissue mobilization techniques, and now the introduction of low-profile plates and bony fillers allows surgeons to reconstruct the skull without creating defects that may be disfiguring or palpable (Fig. 7).

\section{Frontiers of Cerebral Aneurysm Treatment}

With the advent of novel tools and techniques, the treatment of cerebral aneurysms is likely to evolve and improve. Although an exhaustive list of nonmicrosurgical and nonendovascular techniques in development is beyond the scope of this manuscript, two upcoming platforms deserve attention. The first is the application of progenitor cell or regenerative medicine approaches, in which cells, growth factors, or cell and growth factor combinations are administered to assist with the healing of injured endothelial surfaces, thereby repairing the aneurysmal change in the blood vessel wall. ${ }^{2}$ A second approach is the application of nextgeneration genome and transcriptome sequencing, ${ }^{10,19,21,42}$ using patient aneurysm samples that allow for identification of novel, potentially targetable pathways involved in aneurysm formation. These approaches provide unprecedented insight into the biological pathways involved in endothelial cell damage, remodeling, and regeneration, and they can be harnessed for potential medical treatment.

\section{Conclusions}

Innovation has been the driving force making cerebrovascular surgery safer and more effective. The indisputable growth of endovascular techniques is a testament to the visionary practitioners and pioneers who have led this field to equipoise with the surgical treatment of aneurysms. Nonetheless, the surgical treatment of aneurysms has undergone a period of innovation and improvement in an effort to meet the raised bar set by endovascular techniques and practitioners. The new era of aneurysm treatment is upon us, and more practitioners are armed with tools of both surgery and endovascular interventions to provide patients with the best treatment options. Over the next decade, these tools, surgery, and interventions will be unified into a single arsenal rather than remain as divisive camps, which should improve outcomes of patients afflicted with aneurysms.

\section{Acknowledgments}

We acknowledge the support of the Neuroscience Publications staff at Barrow Neurological Institute.

\section{References}

1. Abdulrauf SI, Sweeney JM, Mohan YS, Palejwala SK: Short segment internal maxillary artery to middle cerebral artery bypass: a novel technique for extracranial-to-intracranial bypass. Neurosurgery 68:804-809, 2011

2. Adibi A, Sen A, Mitha AP: Cell therapy for intracranial aneurysms: a review. World Neurosurg 86:390-398, 2016

3. Arnaout OM, El Ahmadieh TY, Zammar SG, El Tecle NE, Hamade YJ, Aoun RJ, et al: Microsurgical treatment of previously coiled intracranial aneurysms: systematic review of the literature. World Neurosurg 84:246-253, 2015

4. Bendok BR, Gupta DK, Rahme RJ, Eddleman CS, Adel JG, Sherma AK, et al: Adenosine for temporary flow arrest during intracranial aneurysm surgery: a single-center retrospective review. Neurosurgery 69:815-821, 2011

5. Berkhemer OA, Fransen PS, Beumer D, van den Berg LA, Lingsma HF, Yoo AJ, et al: A randomized trial of intraarterial treatment for acute ischemic stroke. N Engl J Med 372:11-20, 2015

6. Campbell BC, Mitchell PJ, Kleinig TJ, Dewey HM, Churilov $\mathrm{L}$, Yassi N, et al: Endovascular therapy for ischemic stroke with perfusion-imaging selection. N Engl J Med 372:10091018, 2015

7. Chalouhi N, Bovenzi CD, Thakkar V, Dressler J, Jabbour P, Starke RM, et al: Long-term catheter angiography after aneurysm coil therapy: results of 209 patients and predictors of delayed recurrence and retreatment. J Neurosurg 121:11021106,2014

8. Crowley RW, Ducruet AF, Kalani MY, Kim LJ, Albuquerque FC, McDougall CG: Neurological morbidity and mortality associated with the endovascular treatment of cerebral arteriovenous malformations before and during the Onyx era. J Neurosurg 122:1492-1497, 2015

9. Davies JM, Lawton MT: Advances in open microsurgery for cerebral aneurysms. Neurosurgery 74 (Suppl 1):S7-S16, 2014

10. Farlow JL, Lin H, Sauerbeck L, Lai D, Koller DL, Pugh E, et al: Lessons learned from whole exome sequencing in multiplex families affected by a complex genetic disorder, intracranial aneurysm. PLoS One 10:e0121104, 2015

11. Fischer G, Stadie A, Reisch R, Hopf NJ, Fries G, BöcherSchwarz H, et al: The keyhole concept in aneurysm surgery: results of the past 20 years. Neurosurgery 68 (1 Suppl Operative):45-51, 2011 
12. Gardner PA, Vaz-Guimaraes F, Jankowitz B, Koutourousiou M, Fernandez-Miranda JC, Wang EW, et al: Endoscopic endonasal clipping of intracranial aneurysms: surgical technique and results. World Neurosurg 84:1380-1393, 2015

13. Goyal M, Demchuk AM, Menon BK, Eesa M, Rempel JL, Thornton J, et al: Randomized assessment of rapid endovascular treatment of ischemic stroke. N Engl J Med 372:10191030, 2015

14. Hwang PYK, Tee JW: Keyhole concept in aneurysm surgery. Neurosurgery 69:E1186-E1187, 2011 (Letter)

15. Jovin TG, Chamorro A, Cobo E, de Miquel MA, Molina CA, Rovira A, et al: Thrombectomy within 8 hours after symptom onset in ischemic stroke. N Engl J Med 372:2296-2306, 2015

16. Kalani MY, Elhadi AM, Ramey W, Nakaji P, Albuquerque FC, McDougall CG, et al: Revascularization and pediatric aneurysm surgery. J Neurosurg Pediatr 13:641-646, 2014

17. Kalani MY, Ramey W, Albuquerque FC, McDougall CG, Nakaji P, Zabramski JM, et al: Revascularization and aneurysm surgery: techniques, indications, and outcomes in the endovascular era. Neurosurgery 74:482-498, 2014

18. Kalani MY, Rangel-Castilla L, Ramey W, Nakaji P, Albuquerque FC, McDougall CG, et al: Indications and results of direct cerebral revascularization in the modern era. World Neurosurg 83:345-350, 2015

19. Kurki MI, Gaál EI, Kettunen J, Lappalainen T, Menelaou A, Anttila V, et al: High risk population isolate reveals low frequency variants predisposing to intracranial aneurysms. PLoS Genet 10:e1004134, 2014

20. Little AS, Liu S, Beeman S, Sankar T, Preul MC, Hu LS, et al: Brain retraction and thickness of cerebral neocortex: an automated technique for detecting retraction-induced anatomic changes using magnetic resonance imaging. Neurosurgery 67 (3 Suppl Operative):ons277-ons282, 2010

21. Liu D, Han L, Wu X, Yang X, Zhang Q, Jiang F: Genomewide microRNA changes in human intracranial aneurysms. BMC Neurol 14:188, 2014

22. McDougall CG, Spetzler RF, Zabramski JM, Partovi S, Hills NK, Nakaji P, et al: The Barrow Ruptured Aneurysm Trial. J Neurosurg 116: 135-144, 2012

23. Molyneux A, Kerr R, Stratton I, Sandercock P, Clarke M, Shrimpton J, et al: International Subarachnoid Aneurysm Trial (ISAT) of neurosurgical clipping versus endovascular coiling in 2143 patients with ruptured intracranial aneurysms: a randomised trial. Lancet 360:1267-1274, 2002

24. Nelson PK, Lylyk P, Szikora I, Wetzel SG, Wanke I, Fiorella D: The pipeline embolization device for the intracranial treatment of aneurysms trial. AJNR Am J Neuroradiol 32:34-40, 2011

25. Nossek E, Costantino PD, Eisenberg M, Dehdashti AR, Setton A, Chalif DJ, et al: Internal maxillary artery-middle cerebral artery bypass: infratemporal approach for subcranialintracranial (SC-IC) bypass. Neurosurgery 75:87-95, 2014

26. Paladino J, Mrak G, Miklić P, Jednacak H, Mihaljević D: The keyhole concept in aneurysm surgery-a comparative study: keyhole versus standard craniotomy. Minim Invasive Neurosurg 48:251-258, 2005

27. Ponce FA, Spetzler RF, Han PP, Wait SD, Killory BD, Nakaji P, et al: Cardiac standstill for cerebral aneurysms in 103 patients: an update on the experience at the Barrow Neurological Institute. Clinical article. J Neurosurg 114:877-884, 2011

28. Raabe A, Nakaji P, Beck J, Kim LJ, Hsu FP, Kamerman JD, et al: Prospective evaluation of surgical microscope- integrated intraoperative near-infrared indocyanine green videoangiography during aneurysm surgery. J Neurosurg 103:982-989, 2005

29. Reisch R, Fischer G, Stadie A, Kockro R, Cesnulis E, Hopf $\mathrm{N}$ : The supraorbital endoscopic approach for aneurysms. World Neurosurg 82 (6 Suppl):S130-S137, 2014

30. Reisch R, Marcus HJ, Hugelshofer M, Koechlin NO, Stadie A, Kockro RA: Patients' cosmetic satisfaction, pain, and functional outcomes after supraorbital craniotomy through an eyebrow incision. J Neurosurg 121:730-734, 2014

31. Saatci I, Geyik S, Yavuz K, Cekirge HS: Endovascular treatment of brain arteriovenous malformations with prolonged intranidal Onyx injection technique: long-term results in 350 consecutive patients with completed endovascular treatment course. J Neurosurg 115:78-88, 2011

32. Sanai N, Zador Z, Lawton MT: Bypass surgery for complex brain aneurysms: an assessment of intracranial-intracranial bypass. Neurosurgery 65:670-683, 2009

33. Saver JL, Goyal M, Bonafe A, Diener HC, Levy EI, Pereira VM, et al: Stent-retriever thrombectomy after intravenous t-PA vs. t-PA alone in stroke. N Engl J Med 372:2285-2295, 2015

34. Siasios I, Kapsalaki EZ, Fountas KN: The role of intraoperative micro-Doppler ultrasound in verifying proper clip placement in intracranial aneurysm surgery. Neuroradiology 54:1109-1118, 2012

35. Spetzler RF, McDougall CG, Albuquerque FC, Zabramski JM, Hills NK, Partovi S, et al: The Barrow Ruptured Aneurysm Trial: 3-year results. J Neurosurg 119:146-157, 2013

36. Spetzler RF, McDougall CG, Zabramski JM, Albuquerque FC, Hills NK, Russin JJ, et al: The Barrow Ruptured Aneurysm Trial: 6-year results. J Neurosurg 123:609-617, 2015

37. Spetzler RF, Sanai N: The quiet revolution: retractorless surgery for complex vascular and skull base lesions. J Neurosurg 116:291-300, 2012

38. Streefkerk HJ, Wolfs JF, Sorteberg W, Sorteberg AG, Tulleken CA: The ELANA technique: constructing a high flow bypass using a non-occlusive anastomosis on the ICA and a conventional anastomosis on the SCA in the treatment of a fusiform giant basilar trunk aneurysm. Acta Neurochir (Wien) 146:1009-1019, 2004

39. Vajkoczy P, Korja M, Czabanka M, Schneider UC, Reinert M, Lehecka M, et al: Experience in using the excimer laserassisted nonocclusive anastomosis nonocclusive bypass technique for high-flow revascularization: Mannheim-Helsinki series of 64 patients. Neurosurgery 70:49-55, 2012

40. Washington CW, Derdeyn CP, Chicoine MR, Cross DT, Dacey RG, Moran CJ, et al: Comparing routine versus selective use of intraoperative cerebral angiography in aneurysm surgery: a prospective study. J Neurointerv Surg 8:75-80, 2016

41. Washington CW, Zipfel GJ, Chicoine MR, Derdeyn CP, Rich $\mathrm{KM}$, Moran CJ, et al: Comparing indocyanine green videoangiography to the gold standard of intraoperative digital subtraction angiography used in aneurysm surgery. J Neurosurg 118:420-427, 2013

42. Yasuno K, Bilguvar K, Bijlenga P, Low SK, Krischek B, Auburger G, et al: Genome-wide association study of intracranial aneurysm identifies three new risk loci. Nat Genet 42:420-425, 2010

\section{Disclosures}

The authors report no conflict of interest. 